\title{
The Effects of Continuous Naltrexone Infusions on Diet Preferences Are Modulated by Adaptation to the Diets
}

\author{
BLAKE A. GOSNELL AND DEAN D. KRAHN \\ University of Michigan Medical Center, Department of Psychiatry \\ MSRB-1, A520A, Box 0656, Ann Arbor, MI 48109-0656
}

Received 11 July 1991

\begin{abstract}
GOSNELL, B. A. AND D. D. KRAHN. The effects of continuous naltrexone infusions on diet preferences are modulated by adaptation to the diets. PHYSIOL BEHAV 51(2) 239-244, 1992. - Two groups of male rats were placed on a feeding regimen in which a fat/protein diet and a carbohydrate/protein diet were available ad lib. Naltrexone was infused via osmotic minipumps either at the time the diets were introduced or after one week of adaptation to the diets. In rats adapted to the diets, naltrexone caused a decrease in the intakes of fat/protein and carbohydrate/protein diets. Relative preferences for the two diets were generally unchanged. In contrast, when naltrexone was infused at the time of introduction of the diets, a polarization phenomenon was observed: rats tended to consume nearly all of their daily calories from either one diet or the other. Six rats (out of 10) showed a stronger preference for the carbohydrate/protein diet than did any of the saline-treated rats, while 3 showed a stronger preference for the fat/protein diet than did any of the saline-treated rats. Thus, the effect was not diet- or macronutrient-specific. These preferences became significantly less extreme after termination of naltrexone infusions. Conditioned aversions and naltrexoneinduced reductions in exploratory behavior are discussed as potential explanations for this polarization effect. These results indicate that naltrexone has differential effects on the development versus the maintenance of diet preferences. Further, they emphasize the importance of examining individual differences as well as baseline preferences in studies on the control of intake and diet selection.
\end{abstract}

Naltrexone Opioids Food intake Diet selection Feeding Fat Carbohydrate Macronutrient

FOOD intake, diet selection and/or taste preferences have been shown to be influenced by the administration of opioid agonists and antagonists. A currently favored hypothesis is that opioids play a role in mediating the pleasurable or rewarding aspects of food $(9,39)$. Naloxone reduces the intake of palatable foods and fluids, whereas opioid agonists cause increases in intake $(6,8$, $17,18,21,26,27)$. It has also been reported that in self-selection experiments, opioid agonists and naloxone cause preferential changes in the intake of fat, particularly when rats are foodrestricted $(31,33,38,41,42)$. We have recently reported, however, that baseline preferences for the test diets are important determinants of the effect of morphine on intake (16). There were marked differences between rats in their baseline daily intakes of a fat/protein diet vs. a carbohydrate/protein diet. In rats with a baseline preference for the fat diet, morphine primarily stimulated fat intake. In carbohydrate-preferring rats, however, morphine primarily stimulated intake of the carbohydrate diet. Thus, the effect of morphine appeared to be preference-specific rather than macronutrient-specific. Similarly, Evans and Vaccarino (12) found that morphine stimulated intake of a protein-rich diet in protein-deprived rats, and slightly increased intake of a carbohydrate-rich diet in carbohydrate-deprived rats.

Most studies of the type described above were performed with rats previously adapted to the test diets, i.e., after rats have learned about both the pre- and postabsorptive consequences of the initially novel diets. There is some evidence that opioids may be involved in the acquisition of taste preferences. Leshem (23) found that after repeated pairings of morphine injections with either sucrose or quinine solutions, the preference for sucrose increased, whereas the aversion to quinine was enhanced. Lynch (27) reported that daily treatment with naloxone blocked the acquisition of saccharin preferences. Conversely, treatment with the kappa agonist U-50,488H consistently facilitated the intake of $20 \%$ sucrose (28). In the experiment reported here, we examined the effect of opioid receptor blockade in rats with no previous experience with dietary self-selection of specially formulated test diets. This effect was compared to that obtained with rats allowed to adapt to the diets prior to receptor blockade.

\section{METHOD}

Twenty male Sprague-Dawley rats (Charles River, Wilmington, MA) were individually housed in stainless steel cages in a room in which the lights were on from 7 a.m. to 7 p.m. They were maintained on standard lab chow (Purina No. 5001) from the time of arrival into the lab until the beginning of the experiment. Five days after arrival, each rat was anesthetized with ether and an osmotic minipump was implanted subcutaneously in the interscapular region (Alzet pump model No. 2001, Alza Corp., Palo Alto, CA). These minipumps, with a nominal flow 
TABLE

COMPOSITION OF DIETS

\begin{tabular}{lcc}
\hline & \multicolumn{2}{c}{ Diet } \\
& Carbohydrate/Protein & Fat/Protein \\
\hline & & \\
Com Starch & 919.4 & - \\
Dextrin & 459.6 & - \\
Sucrose & 153.2 & 429.8 \\
*Casein & 429.8 & 6.4 \\
DL-Methionine & 6.4 & 647.0 \\
Vegetable Shortening & - & 34.0 \\
Safflower Oil & - & 20.0 \\
†AIN-76A Vitamin Mix & 20.0 & 70.0 \\
$\dagger$ AIN-76 Mineral Mix & 70.0 & 4.0 \\
Choline Chloride & 4.0 & 100.0 \\
Cellulose (Alphacel) & 100.0 & 1311.2 \\
Weight (g) & 2162.4 & 7813.1 \\
†Total Energy (kcal) & 7812.9 & 5.96 \\
Energy Density (kcal/g) & 3.61 & \\
\hline
\end{tabular}

All components are expressed as weight (grams).

*Assuming a protein content of $90 \%$. tively.

$\dagger$ The vitamin and mineral mixes contain 97 and $12 \%$ sucrose. respec-

$\ddagger$ Based on energy values of 4,9 and $4 \mathrm{kcal} / \mathrm{g}$ for carbohydrate, fat and protein.

rate of $1 \mu \mathrm{l} / \mathrm{h}$ and capacity of $200 \mu \mathrm{l}$, contained either $0.9 \%$ saline $(\mathrm{n}=10)$ or naltrexone hydrochloride $(65 \mathrm{mg} / \mathrm{ml})(\mathrm{n}=10)$ filtered through a $22 \mu^{2}$ syringe filter. Naltrexone was purchased from Sigma Chemical Co. (St. Louis, MO). Rats that received naltrexone weighed $308 \pm 2 \mathrm{~g}$ at the time of surgery. Thus, naltrexone was delivered at an average initial dose of 211 $\mu \mathrm{g} / \mathrm{kg} / \mathrm{h}$. Pumps were filled the day before implantation and primed by placing them overnight in physiological saline at room temperature. Food was withdrawn at the time of surgery; later the same day (approximately 4-7 h after surgery), two separate diets were placed into each cage: a carbohydrate/protein diet (CP) and a fat/protein diet (FP). On a caloric basis, both diets contained equivalent amounts of protein $(20 \%)$, vitamins, minerals, choline and fiber (see Table 1). All components of the diets were purchased from ICN Biochemicals (Cleveland, $\mathrm{OH}$ ), with the exception of DL-methionine (Sigma Chemical Co., St. Louis, MO), choline chloride (Mallinckrodt, Paris, KY) and vegetable shortening (Crisco, purchased locally). The two diets were available ad lib, and intakes were measured every day at approximately the same time (10 a.m. to noon). Positions of the two diet jars in the cages were reversed daily. Body weights were also measured daily. Seven days later, rats were again anesthetized with ether, and the minipumps were replaced. Rats that initially were given saline-filled pumps were given pumps containing naltrexone $(75 \mathrm{mg} / \mathrm{ml})$, and rats that initially had naltrexone-filled pumps were given pumps containing saline. One rat died during this procedure. Data from this rat were deleted in all analyses involving comparisons over time. At the time of implantation, rats receiving naltrexone weighed $353 \pm$ $7 \mathrm{~g}$. Thus, the average initial dose was $212 \mu \mathrm{l} / \mathrm{kg} / \mathrm{h}$. As before, the CP and FP diets were returned approximately $4-7 \mathrm{~h}$ after surgery, and ad lib intakes and body weights were measured daily. Seven days after this second pump implantation, all pumps were removed (under ether anesthesia), and intakes and body weight measures continued for 7 more days.

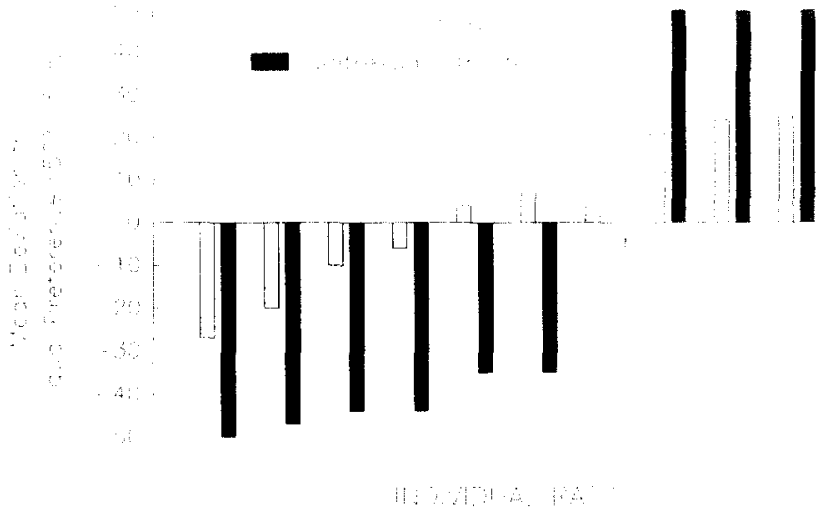

FIG. 1. Diet preferences of rats treated with either saline or naltrexone ( $n=10$ /group). Preferences are based on the number of calories consumed from the fat/protein diet during treatment days 6 and 7, expressed as a percentage of total caloric intake. Scores indicate deviations from an equal preference for the two diets $(50 \%-50 \%)$ : positive values indicate a relative preference for the fat/protein diet, and negative values indicate a relative preference for the carbohydrate/protein diet. Rats were rank-ordered within each group for purposes of illustration. *One rat's deviation score was zero, which indicates an equal preference for the two diets.

To determine the effect of naltrexone on food intake in rats adapted to the diets (Saline-NTX-Ctl group), the intakes on the final 2 days of the saline infusion period were averaged. Intakes of each diet on subsequent days were compared to these baseline values with Dunnett's test (two-tailed). Body weights and preference scores were analyzed with a two-factor analysis of variance (ANOVA: group $\times$ treatment period). Comparisons between groups were tested with $t$-tests; comparisons within a group (repeated measures) were tested with Bonferroni or Dunnett tests (all two-tailed). For all comparisons, the error terms were based only on the two groups being compared.

\section{RESULTS}

It was noted early in the experiment that rats given naltrexone at the time the two diets were introduced appeared to be at the extremes in terms of diet preferences. Such extremes were not noted in the saline-treated rats. To illustrate this, preference for the fat/protein diet was computed for each rat by expressing intake of this diet (in kcal) over the final two days of the infusion period as a percentage of total caloric intake for this period. These percentages were then converted into deviation scores by subtracting $50 \%$. Thus, a deviation score of $50 \%$ indicated an exclusive consumption of the fat/protein diet, whereas a deviation score of $-50 \%$ indicated exclusive consumption of the carbohydrate/protein diet. For purposes of illustration in Fig. 1, rats in each group were rank-ordered from low to high. It is clear that naltrexone-treated rats were more extreme in their diet choices: six rats showed a stronger preference for the carbohydrate/protein diet than did any of the saline-treated rats, while 3 showed a stronger preference for the fat/protein diet than did any of the saline-treated rats.

Naltrexone clearly caused a reduction in total caloric intake. This effect dissipated over days, however, such that intake on the final days was approximately normal. To determine the effects of naltrexone on diet selection, only data from the salinenaltrexone-control group were considered. In addition, data from one rat were deleted from this analysis only, as this rat differed 


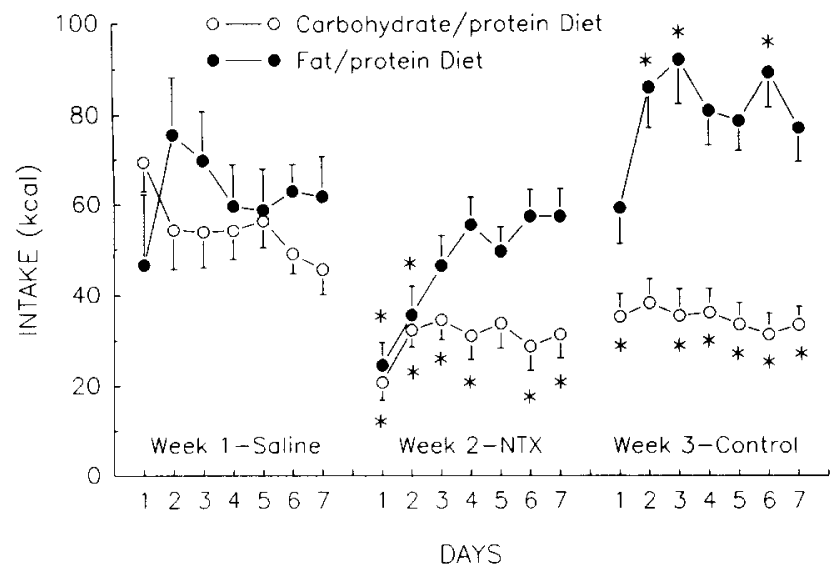

FIG. 2. Daily intakes of the fat/protein and carbohydrate/protein diets (mean \pm s.e.m.) in rats receiving infusions of saline during week 1, naltrexone during week 2 and no infusions during week $3(n=9)$. Asterisks indicate significant differences in mean intake when compared to average mean intakes for days 6 and 7 of week 1 (Dunnett's test, two-tailed, $p<0.05$ ).

from all others in the group by developing an extreme preference for the carbohydrate diet. Data from this rat were included in considerations of variability in diet preferences, total intake and body weight (Figs. 1, 3 and 4). As discussed above, rats receiving naltrexone at the time the diets were introduced developed extreme diet preferences which precluded conventional between-group comparisons. Compared to mean intakes on the two days immediately before drug infusions began, naltrexone caused a reduction in total daily intake for each of the 7 infusion days (Dunnett $t$-tests, 2-tailed) (Fig. 2). Following the termination of naltrexone infusions, intake increased and was significantly greater than baseline on day 3 of the postnaltrexone (control) phase. Intake of the carbohydrate/protein diet was significantly decreased on days $1-4$ and 6-7 of the naltrexone infusion period. Following removal of the naltrexone pumps, intake of this diet remained significantly below baseline. Intake of the fat/protein diet was decreased only for days 1 and 2 of the infusion period, after which it gradually returned to control levels. After the termination of naltrexone infusions, fat/protein intake increased above baseline and was significantly elevated on days 2,3 and 6 of this period. Preference for the fat diet (calculated as daily calories consumed from this diet expressed as a percentage of total caloric intake) did not significantly differ from baseline during naltrexone infusion. There was, however, a tendency for this percentage to increase during the course of the infusion period (from $53 \pm 8 \%$ on day 1 of naltrexone infusions to $64 \pm 6 \%$ on day 7). Following termination of drug infusions, fat preference increased and was significantly greater than baseline fat preference on days 3-7.

With such widely varying diet preferences in rats receiving naltrexone at the beginning of the experiment, presentation of mean preferences would be misleading, as the extreme fat-preferring animals tend to balance the extreme carbohydrate-preferring animals, yielding a mean preference for the fat diet of $43 \pm 15 \%$ (mean \pm s.e.m., $n=9$ ) for the last two days of the first treatment week (vs. $53 \pm 6 \%$ fat diet preference for saline-treated rats, $n=10$ ). To compare statistically the "extremism of preference" of the naltrexone- vs. saline-treated animals, the absolute value of the deviation scores described above were used. The means of the absolute deviations for each group were compared

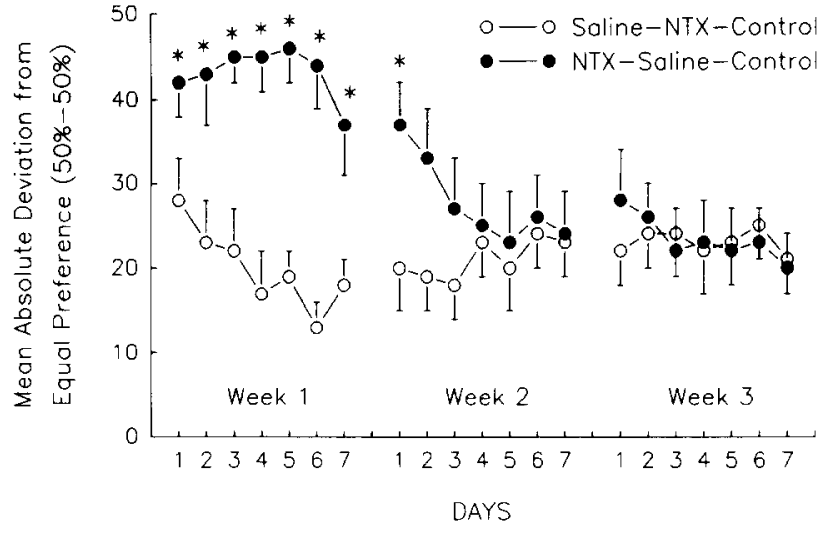

FIG. 3. Absolute deviations (mean \pm s.e.m) from equal preference for the two diets. Rats represented by the open circles received saline and naltrexone infusions during weeks 1 and 2 , respectively $(n=10)$. Rats represented by the closed circles received naltrexone and saline infusions during weeks 1 and 2, respectively $(n=9)$ (on days 1 and 2 of week 1 , one rat consumed no food; $n=8$ on these days). There were no infusions during the third week (control). Asterisks indicate significant differences between the groups $\left({ }^{*} p<0.05\right.$, two-tailed $t$-tests).

with $t$-tests on each day of the experiment. As shown in Fig. 3, rats treated with naltrexone at the beginning were more extreme in their diet choices on each day during infusion. These deviations declined during saline infusions in the following week to a level similar to that observed in the other group. An analysis of variance (group $\times$ treatment week) was used to verify statistically the apparent changes in extremism which occurred over time. In this analysis, an absolute deviation score was based on intakes on the final two days of each week of treatment. The group and week main effects were not significant, $\mathrm{F}(1,17)=2.55$ and $\mathrm{F}(2,34)=1.68$, respectively, $p>0.05$. There was, however, a significant interaction, $F(2,34)=10.82, p<0.001$. Post hoc tests confirmed that in week 1 , naltrexone-treated rats were more "extreme" than saline-treated rats. In contrast, when salinetreated rats were given naltrexone in week 2 , extremism scores did not increase significantly, nor did they change after naltrexone was withdrawn in week 3 . Rats treated with naltrexone in week 1 became significantly less extreme when naltrexone was withdrawn (weeks 2 and 3).

Body weights generally showed the same pattern of changes as that observed with total daily intakes. In both groups of rats, body weights decreased when measured one day after the beginning of naltrexone infusions $(-8 \pm 2 \mathrm{~g}$ and $-22 \pm 3 \mathrm{~g}$ for the Saline-NTX-Control and NTX-Saline-Control groups, respectively). These decreases cannot be attributed to the pump implantation (or removal) procedure alone, as there were either increases (or smaller decreases) in body weight when saline-filled pumps were implanted, as well as when all pumps were removed. An inspection of Fig. 4 indicates that body weight increased at a fairly constant rate within each treatment week. To compare rates of weight gain across groups and treatment periods, daily changes in body weight were averaged for each rat across the final 6 days of each treatment period. Changes following day 1 were omitted to eliminate the potential effects of surgery on weight gain. These rates were analyzed with a two-factor ANOVA (group $\times$ treatment week). The group and week effects were not significant, $\mathrm{F}(1,17)=2.45, p>0.05 ; \mathrm{F}(2,34)=3.06$, $0.05<p<0.10$. There was, however, a significant group $\times$ week interaction, $\mathrm{F}(2,34)=18.81, p<0.001$. In the group receiving naltrexone after adaptation to the diets (Sal-NTX-Ct), naltrex- 

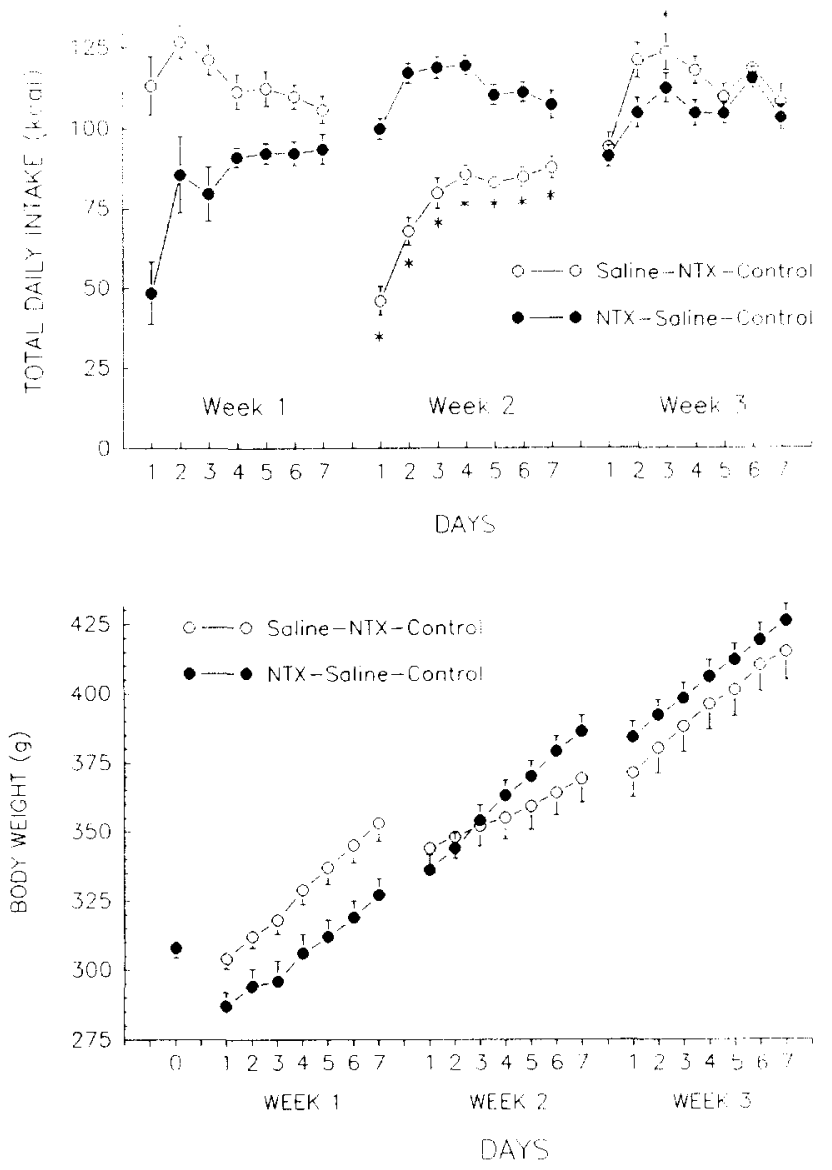

FIG. 4. Upper panel: Total daily caloric intakes (mean \pm s.e.m). Rats represented by the open circles received saline and naltrexone infusions during weeks 1 and 2 , respectively $(n=10)$. Rats represented by the closed circles received naltrexone and saline infusions during weeks 1 and 2 , respectively $(n=9)$. There were no infusions during the third week (control). Asterisks indicate a significant difference in intake for the saline-NTX-control group compared to intakes of this group on days 6 and 7 of week 1 (Dunnett's tests, two-tailed). Lower panel: Body weights (mean \pm s.e.m.) for rats receiving infusions of saline and naltrexone.

one significantly slowed the rate of body weight gain from $8.1 \pm 0.6 \mathrm{~g} /$ day to $4.1 \pm 0.4 \mathrm{~g} /$ day. Following naltrexone removal, this rate significantly increased to prenaltrexone levels $(7.4 \pm 0.6 \mathrm{~g} /$ day $)$. In contrast, rats receiving naltrexone in week 1 gained weight at a rate similar to that of saline-treated rats $(6.6 \pm 0.5 \mathrm{~g} / \mathrm{day})$. Following naltrexone removal, there was a slight, nonsignificant increase to $8.3 \pm 0.4 \mathrm{~g} / \mathrm{day}$. In the week following pump removal (control period, week 3 ), there was a small but significant decrease to $6.9 \pm 0.5 \mathrm{~g} /$ day.

\section{DISCUSSION}

These data indicate that previous exposure to a self-selection paradigm alters feeding responses to naltrexone. In rats adapted to the diets prior to drug infusions, naltrexone reduced total intake but did not change diet preferences. In rats given naltrexone at the time diets were introduced, a "polarization" phenomenon was observed: rats tended to consume nearly all of their daily calories from either one diet or the other. These preferences generally became less extreme following drug with- drawal. Extreme preferences for both diets were obsered whic suggests that the effect of the drug was not diet specti:

The primary goal of this experiment was to determine the 1 fect of naltrexone on the development and maintenance of diet preferences. This goal mandated that one group of rats be given naltrexone before baseline preferences for the diets could be established. It is possible that the extreme preferences ubserved were not caused by the drug, and would have been observed even if no manipulations had occurred. We consider this posibility unlikely for three reasons: $1 /$ preferences this extrente did not occur as frequently in the group that received saline first. 2) the extreme preferences dissipated following naltrexone withdrawal, and 3) in previous work with these diets. We have not observed such a high frequency of extreme preferences

A rat's responsiveness to novel stimuli may be an important factor in determining the initial response to novel diets as well as the eventual development of a preference or aversion. It has been reported that naloxone and naltrexone reduce exploratory and/or locomotor activity elicited by exposure to a novel environment (1, 13, 20, 22). Conversely, low doses of opioid agonists cause increases in exploratory and/or locomotor activity (4.5). A naltrexone-induced decrease in exploration might decrease the likelihood that a novel diet is sampled enough to al low development of a preference. In the present experiment, the extreme diet preferences of naltrexone-treated rats may be viewed as a failure to acquire a preference for one of the diets. given that saline-treated rats generally displayed a more equal prefer. ence for the diets. Similarly, Lynch (27) has shown that treatment with naloxone before daily 1 -h sessions with access to saccharin solution inhibited rats acquisition of a preference for the solution. Daily treatment with a selective kappa opioid agonist, U-50.488H. facilitated the intake of a $20 \%$ sucrose solution (28).

If naltrexone diminished exploratory activity or responsive ness to novel stimuli, it must be asked why the intakes of both diets were not decreased equally, since both were novel at the beginning of the experiment. Given that some rats $(30 \%)$ became almost exclusive fat-preferrers, while others $(60 \%)$ became al most exclusive carbohydrate-preferrers, the extreme preferences do not appear to be due strictly to differences in sensory characteristics of the diets or in postabsorptive or metabolic consequences. The diet that an individual rat finds more "novel" may be related to a predisposition, possibly genetic, to consume fat. That genetics can influence fat preference is illustrated by the difference in self-selection of fat by obese and lean Zucker rats (7). Alternatively, the rats may have initially chosen a ditt randomly. This diet, consumed out of caloric need, may have then acquired the status of being "non-novel." This diet would therefore become the preferred diet, as the naltrexone-treated rat would not be likely to explore for other novel foods. This hypothesis would require that rats form preferences soon after initial exposure, as extreme preferences were observed within the first day of access to the diets. A fine-grained temporal analysis of the development of these preferences might shed additional light on the mechanism underlying the naltrexone effect

Another consideration in the interpretation of the present results is the possibility that naltrexone created a conditioned aversion to a particular diet in rats that were given naltrexone when the diets were first presented. Conditioned taste aversions have been produced in rats by naltrexone delivered orally. subcutaneously and intracerebroventricularly $(36,37)$. In humans, nausea and malaise are sometimes reported after oral administration of naltrexone $(19,29,43)$. It is also known that preexposure to a particular taste attenuates the subsequent conditioned aversion to that taste $(11,40)$. This effect would explain why extreme diet preferences (or aversions) did not occur in rals that 
were familiar with the diets before naltrexone administration. It should be noted, however, that the aversive effects of naloxone, an antagonist pharmacologically similar to naltrexone, cannot completely account for its anorexic or antidipsogenic effects $(14,24)$. In addition, it is not clear why an aversion would be limited to only one diet and why the avoided diet would not be the same for all rats. Both diets were novel when introduced. Based on the preferences of the group that received saline infusions first, rats generally display some preference, though not exclusive, for one diet over the other. It is possible that the stimulus properties of the less preferred diet were more readily associated with any illness or malaise that may have been caused by naltrexone.

In addition to their ability to establish conditioned taste aversions, opioid antagonists have been shown to be effective unconditioned stimuli for the establishment of conditioned place aversions $(10,25)$. We do not believe such conditioning played a significant role in the present experiment because cage positions of the two diets were reversed daily. No consistent fluctuations in day-to-day preferences were apparent.

In rats that were adapted to the diets before drug infusions began, naltrexone caused a decrease in the intakes of both diets. Although intake of the fat/protein diet returned to baseline sooner than did intake of the carbohydrate/protein diet, there were no significant changes from baseline in the percent of total calories consumed from each of the diets over the course of the naltrexone infusion period. This lack of effect on diet preference may reflect the fact that these rats were not generally extreme in their preferences for the diets $(30-75 \%$ fat preference at baseline). In a recently submitted abstract, we found that in rats with approximately equal intakes of the fat and carbohydrate diets, centrally administered naloxone caused approximately equal reductions in the intakes of both diets (15). Similarly, morphine caused increases in the intakes of the two diets in a pattern that roughly paralleled the preferences for these two diets measured prior to injection (16).

Curiously, total caloric intake, fat intake, and preference for the fat diet significantly increased following termination of naltrexone infusions. In rats given naltrexone at the beginning of the experiment, an increase in total intake was also observed af ter removal of the naltrexone pumps. As discussed above, the abnormal preferences in this group precluded conventional comparisons of mean intakes of the two diets. This rebound effect after termination of drug treatment is similar to that reported by Millan and Morris (34). With rats maintained on standard lab chow, they found increases in food and water intake and in body weight after termination of chronic SC naloxone infusions. In contrast, Marks-Kaufman and Kanarek (33) gave daily IP injec- tions of naloxone to rats allowed to self-select their diets while on a restricted feeding schedule. They found that fat intake was slightly reduced during the injection period and returned to control levels in the postdrug period. Differences in the schedule of drug delivery, the feeding schedule and/or the type of diets used may explain the differences observed after the termination of drug administration. The increases observed in the present report and that of Millan and Morris (34) may be due to a supersensitivity to endogenous opioids in brain systems which play a role in mediating food intake and/or palatability. It is known that chronic opioid antagonist treatment causes an up-regulation of opioid receptors and a supersensitivity to the effects of opioids $(2,35,44,45)$. It will be necessary, however, to test rats with differing baseline diet preferences to determine whether our postnaltrexone results represent a diet-selective effect of opioid receptor up-regulation.

Decreases in body weight and/or weight gain have been reported for a number of opioid antagonists $(3,30,32,34)$. In the present study, naltrexone caused a significant reduction in daily rate of weight gain in rats that received naltrexone after adaptation to the diets. Interestingly, in rats that received naltrexone at the beginning of the experiment, daily rate of weight gain was similar to that of saline-infused rats, even though there was an initial decrease in weight. Although food intake appeared to be depressed to a degree similar to that in the group that received naltrexone after adaptation to the diets, the aforementioned feeding irregularities of the NTX-Saline-Ctl group make this finding difficult to interpret at present.

In summary, we have observed that adaptation to a dietary self-selection regime alters the effects of continuous infusion of an opioid antagonist. In rats adapted to the regime, naltrexone caused a decrease in the intakes of fat/protein and carbohydrate/ protein diets. Relative preferences for the two diets were generally unchanged. In contrast, when naltrexone was infused at the time of introduction of the diets, a polarization phenomenon was observed: rats exhibited extreme preferences for one of the diets. Because these preferences were not directed toward the same diet in all rats, the effect does not appear to be diet- or macronutrient-specific. Naltrexone-induced reductions in exploratory behavior may partially explain this effect. These results emphasize the importance of examining individual differences as well as baseline preferences in studies on the control of intake and diet selection.

\section{ACKNOWLEDGEMENTS}

This research was supported by NIDA Grant DA05471. We thank David Averbach and Chetan Patel for technical assistance.

\section{REFERENCES}

1. Arnsten, A. T.; Segal, D. S. Naloxone alters locomotion and interaction with environmental stimuli. Life Sci. 25:1035-1042; 1979.

2. Bardo, M. T.; Bhatnagar, R. K.; Gebhart, G. F. Chronic naltrexone increases opiate binding in brain and produces supersensitivity to morphine in the locus coeruleus of the rat. Brain Res. 289:223 $234 ; 1983$.

3. Brands, B.; Thornhill, J. A.; Hirst, M.; Gowdey, C. W. Suppression of food intake and body weight gain by naloxone in rats. Life Sci. 24:1773-1778; 1979.

4. Browne, R. G.; Segal, D. S. Behavioral activating effects of opiates and opioid peptides. Biol. Psychiatry 15:77-86; 1980.

5. Cador, M.; Kelley, A. E.; Le Moal, M.; Stinus, L. d-Ala-met-enkephalin injection into the ventral tegmental area: effect on investigatory and spontaneous motor behaviour in the rat. Psychopharmacology (Berlin) 96:332-342; 1988.

6. Calcagnetti, D. J.; Reid, L. D. Morphine and acceptability of puta- tive reinforcers. Pharmacol. Biochem. Behav. 18:567-569; 1983.

7. Castonguay, T. W.; Hartman, W. J.; Fitzpatrick, E. A.; Stern, J. S. Dietary self-selection and the Zucker rat. J. Nutr. 112:796-800; 1982.

8. Cooper, S. J. Effects of opiate agonists and antagonists on fluid intake and saccharin choice in the rat. Neuropharmacology 22:323$328 ; 1983$.

9. Cooper, S. J.; Jackson, A.; Kirkham, T. C.; Turkish, S. Endorphins, opiates and food intake. In: Rodgers, R. J.; Cooper, S. J. eds. Endorphins, opiates and behavioral processes. New York: John Wiley and Sons; $1988: 143-186$.

10. Dymshitz, J.; Lieblich, I. Opiate reinforcement and naloxone aversion, as revealed by place preference paradigm, in two strains of rats. Psychopharmacology (Berlin) 92:473-477; 1987.

11. Elkins, R. L. Attenuation of drug-induced bait shyness to a palatable solution as an increasing function of its availability prior to 
conditioning. Behav. Biol. 9:221-226; 1973.

12. Evans, K. R.; Vaccarino, F. J. Amphetamine- and morphine-induced feeding: Evidence for involvement of reward mechanisms. Neurosci. Biobehav. Rev. 14:9-22; 1990.

13. File, S. E. Naloxone reduces social and exploratory activity in the rat. Psychopharmacology (Berlin) 71:41-44; 1980.

14. Frenk, H.; Rogers, G. H. The suppressant effects of naloxone on food and water intake in the rat. Behav. Neural Biol. 26:23-40; 1979

15. Gosnell, B. A.; Krahn, D. D. Effects of centrally administered naloxone on the intake of carbohydrate and fat. Soc. Neurosci. Abstr., 17:492; 1991

16. Gosnell, B. A.; Krahn, D. D.; Majchrzak, M. J. The effects of morphine on diet selection are dependent upon baseline diet preferences. Pharmacol. Biochem. Behav. 37:207-212; 1990.

17. Gosnell, B. A.; Majchrzak, M. J. Centrally administered opioid peptides stimulate saccharin intake in nondeprived rats. Pharmacol. Biochem. Behav. 33:805-810; 1989.

18. Gosnell, B. A.; Majchrzak, M. J. Effects of a selective mu opioid receptor agonist and naloxone on the intake of sodium chloride solutions. Psychopharmacology (Berlin) 100:66-71; 1990.

19. Jonas, J. M.; Gold, M. S. The use of opiate antagonists in treating bulimia: a study of low-dose versus high-dose naltrexone. Psychiatry Res. 24:195-199; 1988.

20. Katz, R. J. Naltrexone antagonism of exploration in the rat. Int. J. Neurosci. 9:49-51; 1979.

21. Kirkham, T. C. Enhanced anorectic potency of naloxone in rats sham feeding $30 \%$ sucrose: Reversal by repeated naloxone administration. Physiol. Behav. 47:419-426; 1990

22. Koek, W.; Slangen, J. L. Acute effects of naloxone and naltrexone, but lack of delayed effects, on exploratory behavior in the rat. Psychopharmacology (Berlin) 84:383-387; 1984.

23. Leshem, M. Morphine enhances taste preference and aversion: evidence for opiate mediation in reinforcement or memory. IRCS Med. Sci. 11:700; 1983 .

24. Leshem, M. Suppression of feeding by naloxone in rat: a dose-response comparison of anorexia and conditioned taste aversion suggesting a specific anorexic effect. Psychopharmacology (Berlin) 82: $127-130 ; 1984$.

25. Lett, B. T. The painlike effect of gallamine and naloxone differs from sickness induced by lithium chloride. Behav. Neurosci. 99 $145-150 ; 1985$.

26. Levine, A. S.; Murray, S. S.; Kneip, J.; Grace, M.; Morley, J. E. Flavor enhances the antidipsogenic effect of naloxone. Physiol. Behav. $28: 23-25 ; 1982$

27. Lynch, W. C. Opiate blockade inhibits saccharin intake and blocks normal preference acquisition. Pharmacol. Biochem. Behav. 24: $833-836 ; 1986$

28. Lynch, W. C.; Burns, G. Enhancement of sucrose intake by the kappa opioid agonist U-50,488H persists beyond the period of drug exposure. Soc. Neurosci. Abstr. 13:878; 1987.

29. Maggio, C. A.; Presta, E.; Bracco, E. F.; Vasselli, J. R.; Kisseliff,
H. R.; Ptohl. D. N.; Hashim, S. A. Naltrexone and human catmg behavior: A dose-ranging inpatient trial in moderately whese men: Brain Res. Bull. 14:657-661: 1985.

30. Mann, P. E.; Pasternak, G. W.; Hahn, E. F.; Currerı. (j.: Lunin. E.: Bodnar, R. J. Comparison of effects of chronic administration of naloxone and naloxonazine upon food intake and maintenance of body weight in rats. Neuropharmacology 27:349-355: 1988 .

31. Marks-Kaufman, R. Increased fat consumption induced by morphine administration in rats. Pharmacol. Biochem. Behav 16:949.955. 1982.

32. Marks-Kaufman, R.; Balmagiya, T.; Gross, E. Modifications in food intake and energy metabolism in rats as a function of chronic naltrexone infusions. Pharmacol. Biochem. Behav. 20:91!-916, 1984

33. Marks-Kaufman, R.; Kanarek, R. B. Diet selection following a chronic morphine and naloxone regimen. Pharmacol. Biochem. Be hav. 35:665-669; 1990 .

34. Millan, M. J.; Morris. B. J. Long-term blockade of $\mu$-opioid receptors suggests a role in control of ingestive behavior, body weight and core temperature in the rat. Brain Res. 450:247-258; 1988.

35. Millan, M. J.; Morris, B. J.; Herz, A. Antagonist-induced opioid receptor up-regulation. I. Characterization of supersensitivity to selective mu and kappa agonists. J. Pharmacol. Exp. Ther 247:721 728; 1988

36. Mucha, R. F. Taste aversion involving central opioid antagonism is potentiated in morphine-dependent rats. Life Sci. 45:671-678; 1989.

37. Mucha, R. F. High-dose oral naltrexone: aversive response in drugnaive rat. Biol. Psychiatry 27:543-545; 1990.

38. Ottaviani, R.; Riley, A. L. Effect of chronic morphine administration on the self-selection of macronutrients in the rat. Nutr. Behav. 2:27-36; 1984

39. Reid, L. D. Endogenous opioid peptides and regulation of drinking and feeding. Am. J. Clin. Nutr. 42:1099-1132; 1985.

40. Revusky, S. H.; Bedarf, E. W. Association of illness with prior ingestion of novel foods. Science 155:219-220; 1967.

41. Romsos, D. R.; Gosnell, B. A.; Morley, J. E.; Levine, A. S. Ef fects of kappa opiate agonists, cholecystokinin and bombesin on in take of diets varying in carbohydrate-to-fat ratio in rats. $\mathrm{y}$. Nutr $117: 976-985 ; 1987$.

42. Shor-Posner, G.; Azar, A. P.; Filart, R.; Tempel, D.; Leibowitz. S. F. Morphine-stimulated feeding: Analysis of macronutrient selection and paraventricular nucleus lesions. Pharmacol. Biochem. Behav. 24:931-939; 1986.

43. Spiegel, T. A.; Stunkard, A. J.; Shrager, E. E.; O'Brien, C. P. Morrison, M. F.: Stellar, E. Effect of naltrexone on food intake. hunger and satiety in obese men. Physiol. Behav. 40:135-141, 1987.

44. Tempel, A.; Gardner, E. L.; Zukin, R. S. Neurochemical and functional correlates of naltrexone-induced opiate receptor up-regulation J. Pharmacol. Exp. Ther. 232:439-444; 1985.

45. Yoburn, B. C.; Inturrisi, C. E. Modification of the response to opioid and nonopioid drugs by chronic opioid antagonist treatment. Life Sci. 42:1689-1696: 1988 . 